\title{
Acknowledgements of previously published material
}

Chapter 3, 'The artificial ear and the disability data gap', is derived in part from an article published in History and Technology on 3 September 2019 (C) 2019 The Author(s), available online: https://doi.org/10.1080/07341512.2019.1652435 I would like to extend my thanks to editors Gabriele Balbi, Christiana Berth, Amy Slaton and Tiago Saraiva, as well as publishers Taylor \& Francis for allowing me to reproduce this material.

Thank you to Clare Jones for giving me permission to reframe some of the material for my Chapter 3 section on 'Case studies: individual users versus institutional innovations', which was originally published as: McGuire, C., 'Inventing Amplified Telephony: The Co-Creation of Aural Technology and Disability', in C. Jones (ed.), Rethinking Modern Prostheses in Anglo-American Commodity Cultures, 1820-1939 (Manchester: Manchester University Press, 2017), pp. 70-90.

Thank you to Havi Carel, Adam Cureton, David Wasserman and Oxford University Press for giving me permission to reframe the material in the Chapter 4 section 'Putting the user in the picture' and in the Chapter 6 section 'The Bragg-Paul Pulsator', some portions of which were originally published as: McGuire, C., and Carel, H., 'The Visible and the Invisible: Disability, Assistive Technology, and Stigma', in D. T. Wasserman and A. Cureton (eds), The Oxford Handbook of Philosophy and Disability (Oxford: Oxford University Press, 2019), pp. 598-615.

Chapter 5, 'The spirometer and the normal subjects', is derived in part from an article published in the British Journal of the History of Science. I would like to extend my thanks to Trish Hatton and editors Charlotte Sleigh and Amanda Rees for allowing me to reproduce this material. McGuire, C. ' $\mathrm{X}$ - Rays Don't Tell Lies”: The Medical Research Council and the Measurement of Respiratory Disability 1936-1945, British Journal for the History of Science, 52:3 (2019), 447-465.

Finally, parts of Chapter 6, 'The respirator and the mechanisation of normal breathing', have been developed alongside my co-authors Jaipreet Virdi and Jenny Hutton and will feature in the forthcoming edited collection Patient Voices in Britain, 1840-1948: Historical and Policy Perspectives, published by Manchester University Press. I am very grateful to Jaipreet and Jenny for their permission to use this work and also extend my gratitude to editors Anne Hanley and Jessica Meyer.

The roles of all these editors in helping me to originally refine this material is much appreciated and their influence has helped to shape the ideas and content of this book in its entirety. 